\title{
The development of food mission: a nutrition- based card game for grade 6 students
}

\author{
Dee Jean $\mathrm{Ong}^{1, *}$ \\ ${ }^{1}$ College of Hospitality Industry Management, Suan Sunandha Rajabhat University, Nakhon Pathom, \\ Thailand
}

\begin{abstract}
Game-based learning is gaining popularity in elementary schools in Thailand. The use of games to teach nutrition education in elementary schools in Thailand is relatively rare. The teaching of nutrition education in the elementary school classrooms in Thailand is predominantly book-based. It can be dry and boring. Therefore, an educational card game called Food Mission is developed to teach elementary school students basic nutrition concepts. This paper explores the perceptions of educational experts, postgraduate students, an elementary science teacher and Grade 6students' responses towards Food Mission educational card game in teaching nutrition education in the classroom. The research participants were two educational experts, eleven postgraduate students, one elementary science teacher and 45 Grade 6 students from a private school in Samut Sakorn Province, Thailand. A pilot study was carried out with seven elementary school students in a home setting prior to the classroom implementation to test the game playability. Interview data was transcribed verbatim. Participants test played the Food Mission card game and found that the educational card game was engaging and fun to play. Elementary school students enjoyed the card game and acquired new vocabulary and basic knowledge about nutrition. This paper discusses the genesis of Food Mission card game and provides guidelines for further modifications of the card game to help elementary students learn basic nutrition concepts.
\end{abstract}

\section{Introduction}

Learning and teaching health and nutrition topic in elementary schools in Thailand can be dry and boring. Traditional classroom learning skews towards drilling, memorization and text-book teaching. Althoughgame-based learning is gaining popularity in elementary schools in Thailand, it is still relatively rare to use games to teach nutrition in the classroom. A number of contrastingly reviews on the pros and cons in game-based learning exist.

Some literature applauds the use of game-based learning in schools while some argues that game-based learning is not the most superior learning method [1]. Some claims about the effectiveness of game-based learning are grounded in existing theory and research, others have little or no empirical evidence [2,3]. Nevertheless, game-based learning is

\footnotetext{
*Corresponding author: dee.on@ssru.ac.th
} 
suitable for nutrition education because it supports several aspects of the learning process [1] such as learners' cognitive, motivational, affective and sociocultural aspects [4,5] as well as academic improvement [6,7, 8,9] and problem-solving skills (Ernest, 1986). Gamebased learning can serve as an edutainment tool [10] and evaluation tool to assess students' understanding of nutrition [11].

This research is designed to explore the educational value of using card games to teach Grade 6 students the basic nutrition concepts in Thailand.

\section{Literature Review}

Cognitive engagement Game-based learning assumes that when students are engaged with the game, they will be motivated to process the game content cognitively, thus resulting in an increase of knowledge gain in their learning [12]. [9] reported that students in the treatment group had greater nutrition knowledge, nutrition attitudes and learning attitudes towards food eating habits than the students in a control group. [13] indicated that Grade 5 students from an elementary school in Taiwan showed improvement in their scientific knowledge of transport and energy after playing the educational card game "Conveyance Go". Yeh et al. (2019) reported that with the introduction of Math-Island game, Grade 2 and 3 students in Taiwan had an increase in their mathematic performance in calculation and word problems. Elementary school students acquired better memorization skills at the English vocabulary with the Dart board game[6]. Vietnamese students acquired new English vocabulary by playing games [14]. In Macedonia, 102 students from five elementary schools reported an increase in their test scores in Math and Social Science subjects with the introduction of traditional games in the classroom environment $[7,15]$.

Motivational and affective engagement Tobar-Munoz et al. [16] reported that elementary school students in the treatment group enjoyed the novel experience of augmented reality game-based learning during reading comprehension activities. In Kocaeli, primary school students' motivation was increased as a result of playing the space and solar system board game [11]. 4th graders in Chen et al. [13] study wanted to play the card game about transportation and energy repeatedly. Game-based learning has a unique way to entice the students and motivate them to enjoy and repeat the experiences $[17,11$, 16].

Collaborative learning and problem solving skills [16] reported that Grade 3 and 6 students collaborated and guided each other in solving problems in the reading activities which was game-based. Augmented reality game-based learning had influenced the students to actively analyze, reflect on the problem, make hypotheses and test their ideas about the reading comprehension questions. [17] claimed that children who played Steeplechase displayed a good understanding of algebraic concepts and had higher level of problem-solving skills in algebra.

Alternative teaching and evaluation tool [11] conducted a study on teachers' response towards the use of board game to teach students space and solar system. They reported that the teachers and students liked the games. Some teachers felt that the board game could be used in the classroom as a teaching tool and as a reinforcement to enhance students' knowledge about space and solar system. Some teachers were not sure how they could use the board game to evaluate students' understanding of the subject matter. Some students had negative feelings towards traditional testing methods and could not express themselves well in paper and pen. Therefore, the test scores were not representative of the students' comprehension of the subject matter. The teachers reported that they found that using games as an evaluation tool provided a more realistic result because some students articulated their understanding during the game play. One advantage of using card games is that card games are easy to make, cost-effective and affordable [10]. 


\section{Research Objectives}

\subsection{This paper has two research objectives:}

To examine the quality of the Food Mission educational card game from educational experts and elementary science teachers' point of view; and

To investigate Grade 6 students' point of view regarding the Food Mission educational card game in helping them to learn basic nutrition concepts.

\subsection{Research Participants and Method}

The research participants were two educational experts, eleven postgraduate students, two elementary science teachers and 45 Grade 6 students from a private school in Samut Sakorn Province, Thailand. A pilot study was carried out with seven elementary school students in a home setting prior to the classroom implementation to test the game playability. An extensive amount of time was invested in the test play with educational experts, postgraduates and elementary science teachers for content verification and game playability.

\subsection{Research Questions}

This paper attempts to answer the research questions:

1)What are the educational experts and elementary school science teachers' response towardsthe quality of the Food Mission educational card game?

2) How do Grade 6 students respond to the Food Mission educational card game in helping them to learn basic nutrition concepts?

\subsection{Food Mission Card Game}

Food Mission card game is an educational card game designed to teach students a number of basic nutrition concepts. These nutrition concepts are based on the Thai food guide model called the Nutrition Flag. The Nutrition Flag is a dietary guideline prepared by the Thailand Ministry of Public Health (MOPH) to educate Thai people about healthy eating. The basic nutrition concepts include the different food groups, the types of foods found in each food group and the amount that should be consumed for each food group. The food groups are rice, rice products, and other starchy foods group, vegetables and fruits group, meat and milk group, oil, sugar and salt group. Ferret Foodie card game is easy and fun to play. It can be easily implemented in the classroom.

\subsection{Game Design and Development Process}

Food Mission card game is designed to teach children the different food groups and simple English vocabulary about foods. Foods selected to be included in the card game are foods that are consumed by Thai population in their daily life. The researcher visited the wet market and talked to the local vendors about the top five types of foods from the vegetable and fruit groups that Thai people like to eat. The researcher also visited a few local restaurants where students frequented in Nakhon Pathom Province and asked the restaurant owners about the top five types of vegetables that Thai students usually order. The researcher asked some parents whom she is acquainted to in Nakhon Pathom Province about their children the types of vegetables and fruits they eat in the school and at home. 
The researcher also asked some local fruit sellers in Nakhon Pathom Province what are the top five fruits that students usually buy. For practical reasons, Nakhon Pathom Province is used as a study site since the researcher is living here. Through informal conversations with the local Thai people, the researcher concluded the food selection. The researcher chose the most popular fruits and vegetables, which are mango, pineapple, watermelon, carrot, cucumber and pumpkin. Rice starchy food included buns, rice and noodles, which are the staple food for Thai people. The researcher included fish, shrimp and chicken in the meat group. Pork and beef are excluded due to cultural sensitivity and religious reasons. Some Thai people are Muslims and they do not eat pork. Buddhism is the official religion in Thailand and most Thai people who practice Buddhism do not eat beef. Milk group included all milk-based products that are found in Thailand.

The researcher used attractive pictures to represent these foods in the card game. The researcher experimented the cards with different sizes and thicknesses to make them childfriendly and durable. The researcher printed a homemade prototype and experimented it with six postgraduate students to verify the content and playability of the card game. It took the researcher about one week to come up with seven different ways to play the card game.

The researcher tried to design the rules to be simple and easy to follow. The researcher used simple English Language with card pictures to write the rules into a user-friendly rule book. The designing, making, printing and cutting of the cards took about one week. The researcher test played it one time with six post-graduate students. It took about 90 minutes to play all the seven variations. The post-graduate students gave the researcher some suggestions to improve the games based on their game-based learning knowledge. With that, the researcher introduced some challenges into the card game. To verify the content and playability, the researcher played it one time with two professors with a group of five new post-graduate students without game-based learning knowledge. The game play took about 30 minutes and only one game was played. The players said that the game was fun and easy to implement with elementary school students. Besides learning about food vocabulary and the different food groups, they said that elementary school students can also learn to ask simple questions using the English Language.

One week later, the researcher conducted a simple pilot study with a group of seven Thai elementary school students in one of the parent's home in Nakhon Pathom Province. These seven elementary school students aged between seven to eleven years old. The researcher informed the parents the objective of the pilot study and sought their consent and cooperation to allow the students to participate in the game play. We test-played all the seven games and they were fun and playable.

The elementary school students liked Go Fish and Food UNO best. Since English language was not the main language used in school and home, the elementary school students had limited English vocabulary. The researcher needed help to explain the rules to the Thai elementary school students in Thai language. The game play was conducted in both Thai and English. During the game play, we encouraged the elementary school students to ask question using English language. At the end of the game, many of them could recognize and name some of the foods in the English language like "shrimp", "pineapple", "pumpkin", "watermelon", "bun" and "vegetable". They could also form simple questions like, "Do you have pineapple?", "Do you have fish?" and make simple sentences like: "I want chicken", "I like mango". They could group the foods correctly. The game play lasted about two hours. Besides nutrition concepts, other skills that were built into the game play were language skills, memory skills, social skills, strategic thinking skills and decision-making skills.

The outcomes from the pilot study was positive. The card game was fun, easy to playand it promoted the various skills amongst the students which it had set out to do. The researcher was much encouraged when all the elementary school students asked when the 
researcher would return again to play another card game with them. They wanted to play the card game and "new" card games again. The researcher noted older children had better memory skills, strategic thinking skills and decision-making skills compared to the younger ones. Regardless of their age, we observed that children were competitive and they wanted to win all the time. This was an aspect we realized was so important to teach children what "fair play" means and the value of losing with grace. Perhaps it will be worthwhile to research the impact of using nutrition-based card game to teach children nutrition topic in the homes in the future. It took the researcher two months to designand test-play the Food Mission card game.

\subsection{Implementation in the classroom}

After the Food Mission card game was test played and the contents verified, the elementary science teacher implemented the card game in the classroom. The teacher used about 20 minutes of the class time to conduct one game of their choice. He pre-trained a number of student leaders prior to the classroom implementation. There were about 22 to 24 students in each Grade 6 class. Students were grouped in groups of 4 to 6 based on class size. Students were placed in mixed-ability groups based on their current-needs [18]. The student leaders were placed in each individual group. Game instruction was given in English. They explained the rules in Thai language to their friends and facilitated the card game. Classroom implementation was completed in 2 sessions and were video-recorded.

\section{Discussion}

From this study, we found that fun was an important element to initiate gameplay. Consistent with Smith [19] and Cordonaet al. [20] findings, elementary school students enjoyed the gameplay because they had fun. They derived enjoyment from playing Food Mission card game because the rules were simple. Findings indicated that Grade 6 students derived enjoyment from playing the card games repeatedly when they are familiar with the game rules. This was most evident in the case of Food UNO amongst the Grade 6 students.

The Food Mission card game had the potential to enhance Grade 6 students' learning about basic nutrition concepts. Several studies suggested that the materials and game content in sustained play could influence students' increased knowledge of science knowledge [10]. The colorful cards and cartoons appeared to appeal to the students. Attractive visual presentations were necessary to promote students' learning interest [11]. Research suggested that visual complexity and graphics helped students to have better understanding of the topic [21].

The elementary teacher found that Grade 6 students were more confident in speaking in English when playing the Food Mission card game. Some students attempted to speak in English during the game play. In "Quartet Card", teachers also reported that the card game motivated the students to speak in English in a playful context [22]. Learning the English language became easier for the students when learning is a fun and easy activity [23]. Topics addressing students' learning needs can make them more enthusiastic about learning [24]. It was also easier for the teachers to teach speaking through the classroom using the card game [22].

The elementary science teacher also reported that the students like Go Fish and Food UNO best because they were easy to play.It seemed that the level of difficulty was dependent on how the students performed in the game. Students' preference for the card game was dependent upon their performance in the game and how easy the game was. The psychological basis of gameplay in learning is constructivism as it helps construct 
knowledge [25]. In "Green Machine”, Miller and et al. [26] reported a similar observation where students learnt recycling processes by taking a system thinking approach to learning.

The elementary science teacher mentioned that pre-training student-leaders has created a positive game-based learning environment. He acted as a facilitator while the studentleaders conducted the game play in each group. Co-construction of learning opportunities happened between teachers and students when teachers adopted the role of empowerers, scouts, scaffolders and assessors [27].

Students' input and feedback should be considered in the game design to make the game more playable [10]. Prototyping and test play for the created card game is essential. Prototyping allows the educational content to be delivered in a playable manner. Playtesting with a target group of students, for example, a mix-aged group of elementary school students in this study helps the card game designer to fix and make the game more fun and playable for the real classroom implementations.

Overall, the findings suggest that the use of educational card games in classrooms can be effectively applied to a wide range of audience and disciplines. Educational card games can be used as supplementary teaching materials for science teachers.

\section{Conclusion}

Food Mission is an enjoyable card game designed to teach Grade 6 students basic nutrition concepts. Generally, Grade 6 students considered Food Mission to be a fun card game for them to learn about food and the five food types. Responses from the users and players (elementary science teacher and students) are really useful to revise the game rules in Food Mission card game. It is envisioned that following implementation of the Food Missioncard game; the elementary science teacher can facilitate subsequent classroom teaching via a game-based learning approach.

\section{Acknowledgement}

The author expresses her gratitude towards the educational experts, post-graduate students, the elementary science teacher'sfeedback and student participation in this research.

\section{References}

1. D. Druckman, Simulation and Gaming Across Disciplines and Cultures: ISAGA At A Watershed (SAGE Publications, New York, 1995)

2. M. Pivec et al., Pers Ubiquit Comput 17, 1647-1661 (2014)

3. O. Sivash et al., IOP Conference Series: Earth and Environmental Science 272(3), 032118 (2019)

4. J.L. Plass et al., Educational Psychologist 50(4), 258-283 (2015)

5. O.V. Zakharchenko et al., J. of Reviews on Global Economics 8, 859-872 (2019)

6. U. Puspasari, A. Malik, Inovish Journal 2(1), 104-119 (2017)

7. V. Trajkovik et al., PLoS ONE 13(8), 1-15 (2018)

8. M.V. Vinichenko et al., Espacios 40(19) (2019)

9. J.M. Yien et al., The Turkish Online J. of Educational Technology 10(2), 1-11 (2011)

10. S. Mostowfi et al., Intern. J. of Environmental and Science Education 11(12), 54535476 (2016) 
11. E.B. Kirikkaya et al., Turkish Online J. of Educational Technology 9(2), 1-14 (2010)

12. G.C. Delacruz, Games as formative assessment environments: Examining the impact of explanations of scoring and incentives on math learning, game performance, and help seeking. CRESST REPORT 796 (The National Center for Research on Evaluation, Standards, and Student Testing, 2011)

13. P.G. Chen et al., Developing an educational card game for science learning in primary education (Fourth International Conference on Digital Game and Intelligent Toy Enhanced Learning) (2012)

14. T.T.H. Nguyen, T.T. Khuat, Asian EFL Journal 18(6) (2003)

15. H.T. Van et al., E3S Web of Conferences 175, 13034 (2020)

16. H. Tobar-Munoz et al., J. of Educational Computing Research, 1-36 (2017)

17. P. Ernest, Mathematics in School 2, 1-8 (1986)

18. Y. Ardasheva et al., The Elementary School J. 120(1), 88-108 (2019)

19. D.R. Smith, Physics Education 38(1), 47-51 (2003)

20. T. Cordona et al., Biochemistry and Molecular Biology Education 35(6), 416-421 (2007)

21. D. Guo et al., Elementary School J. 119(2), 244-269 (2018)

22. Y. Elviza, Ratmanida, J. of English Language Teaching 8(1), 146-152 (2019)

23. M.G. Pratama, S. Fitriani, The Asian ESP J. 16(4), 22-32 (2020)

24. C.Y. Hong, The Asian ESP J. 15(3), 99-125 (2019)

25. S.C. Agarkar, Resonance 84, 7-39 (2019)

26. J.L. et al., J. of Chemical Education 96, 3006-3013 (2019)

27. P.A. Bishop et al., The Elementary School J. 121(2), 311-336 (2020) 